\title{
The Development of an Evaluation Model to Assess the Effect of Online English Teaching Based on Fuzzy Mathematics
}

\author{
https://doi.org/10.3991/ijet.v16i12.23325 \\ Yuqing Zhang \\ Shaanxi University of Science \& Technology, Shaanxi Xi'an, China \\ zhangyqq113@163.com
}

\begin{abstract}
The evaluation of online English teaching effect involves multiple fuzzy factors. This paper attempts to develop a model that fully considers these factors when assessing the effect of online English teaching. Firstly, the constraints and weaknesses lying in online English teaching were enumerated, revealing the key points of improving online English teaching effect. On this basis, several evaluation index systems (EIS) were established for this effect from the perspectives of teachers, students, and administrators. Moreover, an improved multi-attribute fuzzy evaluation model was created for online English teaching effect based on fuzzy mathematics. The proposed model can effectively quantify the effect of online English teaching, and enjoy a good prospect in engineering application.
\end{abstract}

Keywords - Online English teaching, teaching effect, evaluation model, fuzzy mathematics theory, multiple-attribute decision-making

\section{$1 \quad$ Introduction}

Since English is one of the most important lingua franca in the world, English courses have become an indispensable and all-important part of modern education. Over the years, English education has cultivated numerous excellent English professionals and provided good backings for supplying senior talents for various engineering practice. Needless to say, English education is of undoubted necessity [1-4]. As contemporary educational technologies are transforming and upgrading constantly, the teaching mode of English education is undergoing great changes and online English teaching has gradually become a popular teaching mode [5-7], now, it is acting a crucial role in modern education and serving as a catalyst in the cultivation of English professionals [8-10].

As online English teaching is affected by many factors, its teaching quality and teaching effect evaluation have attracted the attention from field scholars and they have conducted research on the said problem from multiple angles. For example, Yan et al. proposed a SPOC-based English teaching quality evaluation index system, which could serve as an evidence for the optimization of the mixed English teaching 
mode [11]. Zhang established an evaluation method based on GA-optimized RBF neural network aiming to assess the quality of English teaching, and his research findings offered a consultation for analyzing the teaching quality and teaching effect of English courses [12]. Chen analyzed the appraisal mode of English teaching in colleges and universities in the context of network technology, and pointed out a few problems existing in the implementation of different network teaching modes [13]. Li discussed how to construct the evaluation system of college English teaching effect under the network mode, and provided a good evaluation method of English teaching effect under the network mode [14]. Wei and Zeng took the online English course teaching as an example and explored an improved comprehensive teaching effect evaluation method of online courses [15].

Since many factors can influence the online English teaching effect and some evaluation indexes are hard to quantify, the evaluation process generally involves multiple attributes, and it is fuzzy and complex. Although existing evaluation index systems and evaluation methods do have certain instructive functions for assessing the effect of online English teaching, their analysis angles are different, and the influencing factors are dynamic and in constant developing. Out of these concerns, this paper attempts to build a set of novel EISs for the target problem and gives a quantitative analysis on it based on the theories and principles of fuzzy systems [16-17].

The structure of the main study contents is arranged in five chapters in this paper: the first chapter points out the research topics of online English teaching and the evaluation of its teaching effect; the second chapter analyzes the relevant influencing factors of such teaching effect; the third chapter establishes a set of multi-perspective evaluation index systems; the fourth part presents an improved multi-attribute fuzzy evaluation model; and the fifth part summarizes and analyzes the research work of this paper.

\section{$2 \quad$ Problems in Online English Teaching}

\subsection{Unsystematic online English teaching content}

Although the teaching forms of online English courses are quite diverse, the teaching content is generally unorganized and messy. The knowledge points are scattered and disordered, and they are taught in an unsystematic way. When students are learning these knowledge points, they can only receive them one-sidedly; the online teaching content fails to systematically impart the English knowledge from multiple aspects of listening, writing, reading, speaking and translating, and as a result, students cannot form a systematic English knowledge structure. Moreover, we all know that English is a language course, and language learning requires students to not only remember the knowledge points of the language, but also have an overall knowledge about the cultural background of the language; all these require the learning to be systematic, so the online English teaching content should give some consideration to this aspect. In addition, the teaching content needs the support of online English teaching courseware, however, there is not much choice for such courseware, and the 
existing ones are not that adaptive to the cultivation of high-quality English professionals or suitable for the essential characteristics of online English teaching; therefore, it is very important to form a systematic online English teaching content system.

\subsection{Unsatisfactory quality of online English teaching resources}

Current, online English teaching lacks the support of good courseware, and the existing ones have some quality problems. Some of them have poor adaptability, some with poor compatibility, and some are left unused, making it difficult for students to use them for their autonomous learning. On the one hand, existing online English teaching courseware cannot motivate students' initiative in learning; on the other hand, English teachers fail to conduct a systematic research and analysis on the characteristics of online education and online courses, they haven't received proper skill training, so they can hardly master related techniques for online education; moreover, in the teaching process, existing courseware cannot make diagnosis according to students' learning status or dynamically adjust the content of online English teaching, therefore, when English teachers are giving online courses, they tend to adopt the traditional English teaching mode and indoctrinate the knowledge to students like force-feeding the ducks. The existing online teaching resources are not as varied, and their upgrade speed is low, there are even less teaching resources for autonomous learning, the knowledge leant by students lacks relevance, therefore, it's hard to realize cultivating students based on their natural ability.

\subsection{Imperfect online English teaching tools}

Online English teaching tools are essential guarantees for enhancing the teaching effect of online English courses. In terms of current online English teaching, although various technologies have been improved day by day, such as network technology, database, video conference, network broadcasting, synchronous communication, and virtual reality, and new intelligent technologies are joining this force constantly, the application of these technologies is not mature enough, and there are technical bottlenecks during online English teaching, which has brought uncertainties to online English teaching quality. Therefore, if we want to effectively improve such quality, we need to ensure the diversity and maturity of online English teaching tools, and make sure that these teaching tools are intelligent and developing constantly.

\subsection{Insufficient interactivity of online English teaching}

An important problem with online English teaching is that the communication and interaction of are insufficient, this problem is reflected in many aspects: first, during online English teaching, teachers and students lack effective communication and exchange, compared with the traditional classroom teaching, online English teaching is mere an indoctrination method, not emotional communication. Second, poor feedback from students, since teachers and students are at different time and space during online teaching, the teaching-learning interactivity is seriously affected; students can- 
not raise questions to the teachers in time, and teachers could not give timely answers. Third, there is a serious lag in the tracking of students' learning status, especially in the process of collaborative learning, due to the weak ability of students in learning communication, the effect of collaborative learning is compromised, and it's difficult to effectively make use of the online English teaching resources. Fourth, the teaching exchanges between English teachers are not well organized, the teaching information sharing and utilization among English teachers is insufficient, which has greatly hindered the development of online English teaching system.

\subsection{Incomplete online English teaching platforms}

As various supporting technologies for online English teaching are developing rapidly, such as artificial intelligence (AI), database, VR, and video conference, online English teaching platforms do have strong technical supports, which have greatly promoted the construction of online English teaching platforms. In terms of system composition, such platforms can be divided into two parts, the hardware part, and the software part; the hardware facilities, such as the bandwidth and network signal transmission quality need further improvement; and the software systems need to work on reliability, intelligence, maintenance and upgrading. Both the two parts require great manpower, material, and financial investment, if such investment is not sufficient enough, even though the platforms do have certain technical supports, they can hardly satisfy the requirements of online English teaching, which would then impact the improvement of the teaching effect, and fail to adapt to the modern online English teaching mode.

\subsection{Incompetent faculty of online English teaching}

Same as the traditional English teaching, online English teaching also needs a good faculty, and the higher the faculty level, the better the teaching effect. As we all know, it is not that developed online teaching techniques and diversified applications would guarantee the teaching effect. Online English teaching is jointly determined by various aspects and factors including the specific English course content, students' English learning requirements, and the teachers' teaching ability and quality, etc., only when these aspects have been well arranged and the resources have been well allocated can the online English teaching receive good teaching effect. Therefore, it is of great significance to cultivate a group of first-line English teachers with solid knowledge reserve, good teaching skills, strong adaptability to network teaching, and excellent ability in absorbing and recreating cyberculture. However, judging from the real situation, current English teachers do not have major shortcomings in professionalism, but they have obvious problems in online teaching technology mastering. Many of them lack the relevant training and their online teaching skills are not good enough. Since very few English teachers have both the good English teaching qualities and the good online teaching skills, the teaching effect and quality of online English courses have been compromised. 


\subsection{Difficulty in online English teaching management}

Generally, various types and forms of information are involved during online teaching, not only the information of course content and course teaching, but also other information irrelevant to the course teaching. At the same time, online English teaching also involves how to effectively supervising the teaching activities of instructors and the learning behaviors and status of learners, as well as online English exams and works, etc., the management of online English teaching is a complex project involving extensive information, and how to manage online English teaching works and the connections between the work links is an essential prerequisite for the successful execution of online English courses and ensuring a good teaching effect.

\subsection{Untransformed teaching concepts of online English teaching}

In contrast to the traditional English teaching in real world classrooms, online English teaching is a brand-new thing and it needs to adopt new teaching modes, and the execution of such new modes requires English teachers to transform their intrinsic teaching concepts, and only the transformed concepts could reflect the essence of online education. However, since the traditional English teaching mode has been adopted for so many years and it has already formed a deep-rooted influence on teachers and students, and it's unrealistic to change it overnight. We need to realize that online English teaching varies greatly when cultivating the thinking of teachers and students, especially in terms of quality education and innovation education, the transformation of their teaching and learning concepts and habits is a gradual changing and adaptation process. At present, the teaching concepts of online English teaching have not been fully transformed, which has resulted in that English teachers and students attach not enough importance to online English teaching, they are not that enthusiast for online English teaching, and their understanding of the depth and breadth of the content of online English teaching is biased, which has also affected the teaching effect and quality of online English courses.

\section{Evaluation Index Systems (EIS) for Online English Teaching Effect}

\subsection{Principles for choosing indexes}

In this study, the evaluation indexes of online English teaching effect were selected according to the scientific, objective, comprehensive, typical, hierarchical, and operable principles, and the evaluation index systems were constructed from the three perspectives of teachers, students, and administrators. 


\subsection{EIS based on teacher perspective}

The EIS based on teacher perspective mainly analyzes teaching-related factors from the perspective of teachers, and judges the role of these factors on the teaching effect of online English courses, see Table 1 below for details.

Table 1. EIS based on teacher perspective

\begin{tabular}{|c|c|}
\hline EIS & Evaluation indexes \\
\hline \multirow{13}{*}{$\begin{array}{l}\text { EIS based on teacher } \\
\text { perspective }\end{array}$} & Completeness of teaching courseware \\
\hline & Systematicness of teaching resources \\
\hline & Rationality of teaching plans \\
\hline & Completion of teaching goals \\
\hline & Fulfillment of teaching tasks \\
\hline & Course content is up-to-date \\
\hline & Teaching knowledge is shared \\
\hline & Online classroom is interactive \\
\hline & Teaching method is advanced \\
\hline & Teaching tool is intelligent \\
\hline & Online teaching quality and professionalism \\
\hline & Online faculty level \\
\hline & Integration of online and offline classrooms \\
\hline
\end{tabular}

\subsection{EIS based on student perspective}

The EIS based on student perspective mainly analyzes the learning-related factors from the perspective of students, and judges the impact of these factors on the teaching effect of online English courses, see Table 2 below for details.

Table 2. EIS based on student perspective

\begin{tabular}{|l|l|}
\hline \multicolumn{1}{|c|}{ EIS } & \multicolumn{1}{c|}{ Evaluation indexes } \\
\hline \multirow{5}{*}{$\begin{array}{l}\text { EIS based on student } \\
\text { perspective }\end{array}$} & Frequency of online course learning \\
\cline { 2 - 2 } & Duration of online course learning \\
\cline { 2 - 2 } & Completion of online course learning tasks \\
\cline { 2 - 2 } & Mastery of professional knowledge points \\
\cline { 2 - 2 } & Futonomous learning initiative \\
\cline { 2 - 2 } & Crequency of interaction in online course learning \\
\cline { 2 - 2 } & Innovation ability of online course learning \\
\cline { 2 - 2 } & Problem solving ability of online course learning \\
\cline { 2 - 2 } & Participation in after-class feedback \\
\cline { 2 - 2 } & Ability to reflect and summarize online course learning \\
\cline { 2 - 2 } & Completion of learning goals \\
\hline
\end{tabular}




\subsection{EIS based on administrator perspective}

The EIS based on administrator perspective mainly analyzes the managing-related factors from the perspective of teaching administrators, and judges the influence of these factors on the teaching effect of online English courses, see Table 3 below for details.

Table 3. EIS based on administrator perspective

\begin{tabular}{|l|l|}
\hline \multicolumn{1}{|c|}{ EIS } & \multicolumn{1}{c|}{ Evaluation indexes } \\
\hline \multirow{5}{*}{$\begin{array}{l}\text { EIS based on administrator } \\
\text { perspective }\end{array}$} & Teaching order of online courses \\
\cline { 2 - 2 } & Teaching planning of online courses is reasonable \\
\cline { 2 - 2 } & Syllabus of online courses is scientific \\
\cline { 2 - 2 } & Teaching concept of teachers is advanced \\
\cline { 2 - 2 } & Ptudent satisfaction \\
\cline { 2 - 2 } & Seer review satisfaction \\
\cline { 2 - 2 } & Eupervisor and society satisfaction \\
\cline { 2 - 2 } & Failure rate of student performance \\
\cline { 2 - 3 } & Absenteeism rate of students \\
\cline { 2 - 2 } & Participation in online course teaching evaluation \\
\hline
\end{tabular}

\section{Multi-Attribute Fuzzy Evaluation Model for Online English Teaching Effect}

The above-established online English teaching effect evaluation index systems show that the evaluation process involves a variety of constraints which might contain uncertain information, therefore, to verify the reliability of the assessment results, it's necessary to establish a fuzzy evaluation model with multiple attributed to assess the effect of online English teaching.

\subsection{The triangular fuzzy number form of online English teaching effect evaluation}

Before assessing the teaching effect, let's suppose there are $m$ evaluation objects and $n$ evaluation indexes, the fuzzy value of the $i$-th $(1 \leq i \leq m)$ object with respect to the $j$-th $(1 \leq j \leq n)$ index is $\tilde{U}_{i j}=\left(u_{i j}^{l e f}, u_{i j}^{o p t}, u_{i j}^{r i g}\right), u_{i j}^{l e f} \leq u_{i j}^{o p t} \leq u_{i j}^{r i g}$. According to the theory of fuzzy mathematics, $u_{i j}^{\text {lef }}$ is defined as the minimum of the fuzzy value of the $i$-th object with respect to the $j$-th index, it represents the lower limit of fuzzy value $\tilde{U}_{i j} ; u_{i j}^{o p t}$ is defined as the median of the fuzzy value of the $i$-th object with respect to the $j$-th index, it describes the most probable value of fuzzy value $\tilde{U}_{i j} ; u_{i j}^{r i g}$ is defined as the maximum of the fuzzy value of the $i$-th object with respect to the $j$-th index, it represents the upper limit of the fuzzy value $\tilde{U}_{i j}$. It can be seen that, greater absolute 
value of $u_{i j}^{r i g}-u_{i j}^{l e f}$ indicates more uncertain information in the fuzzy number; on the contrary, smaller absolute value of $u_{i j}^{r i g}-u_{i j}^{l e f}$ indicates less uncertain information in the fuzzy number; in special cases, the absolute value of $u_{i j}^{r i g}-u_{i j}^{l e f}$ is 0 , namely $u_{i j}^{l e f}=u_{i j}^{o p t}=u_{i j}^{r i g}$, meaning that the measurement value of the $i$-th object of online English teaching effect with respect to the $j$-th index is the most accurate.

\subsection{Fuzzy attribute set and plan set}

Based on the number of objects to be evaluated, the corresponding plan set $\boldsymbol{S}$ of online English teaching effect evaluation could be constructed as:

$$
\mathbf{S}=\left\{S_{1}, S_{2}, \cdots, S_{i}, \cdots, S_{m-1}, S_{m}\right\}
$$

According to index selection principles mentioned in previous chapter, the indexes were determined and the corresponding evaluation index systems from different perspectives were constructed. To facilitate expression, suppose there're $n$ indexes, each index is a fuzzy decision attribute, then the fuzzy attribute set $\boldsymbol{C}$ of the online English teaching effect evaluation is:

$$
\mathbf{C}=\left\{C_{1}, C_{2}, \cdots, C_{i}, \cdots, C_{n-1}, C_{n}\right\}
$$

\subsection{Normalization of fuzzy attribute values of online English teaching effect evaluation}

For the obtained fuzzy value $\tilde{U}_{i j}=\left(u_{i j}^{l e f}, u_{i j}^{o p t}, u_{i j}^{r i g}\right)$ of the $i$-th object with respect to the $j$-th index, the corresponding initial value matrix $\boldsymbol{U}$ of online English teaching effect evaluation can be constructed as:

$$
\begin{aligned}
& \mathbf{U}=\left[\begin{array}{ccccc}
\tilde{U}_{11} & \cdots & \tilde{U}_{1 j} & \cdots & \tilde{U}_{1 n} \\
\vdots & \vdots & \vdots & \vdots & \vdots \\
\tilde{U}_{i 1} & \cdots & \tilde{U}_{i j} & \cdots & \tilde{U}_{i n} \\
\vdots & \vdots & \vdots & \vdots & \vdots \\
\tilde{U}_{m 1} & \cdots & \tilde{U}_{m j} & \cdots & \tilde{U}_{m n}
\end{array}\right] \\
& =\left[\begin{array}{cccccc}
\left(u_{11}^{l e f}, u_{11}^{o p t}, u_{11}^{r i g}\right) & \cdots & \left(u_{1 j}^{l e f}, u_{1 j}^{o p t}, u_{1 j}^{r i g}\right) & \cdots & \left(u_{1 n}^{l e f}, u_{1 n}^{o p t}, u_{1 n}^{r i g}\right) \\
\vdots & & \vdots & \vdots & \vdots & \vdots \\
\left(u_{i 1}^{l e f}, u_{i 1}^{o p t}, u_{i 1}^{r i g}\right) & \cdots & \left(u_{i j}^{l e f}, u_{i j}^{o p t}, u_{i j}^{r i g}\right) & \cdots & \left(u_{i n}^{l e f}, u_{i n}^{o p t}, u_{i n}^{r i g}\right) \\
\vdots & & \vdots & \vdots & \vdots & \vdots \\
\left(u_{m 1}^{l e f}, u_{m 1}^{o p t}, u_{m 1}^{r i g}\right) & \cdots & \left(u_{m j}^{l e f}, u_{m j}^{o p t}, u_{m j}^{r i g}\right) & \cdots & \left(u_{m n}^{l e f}, u_{m n}^{o p t}, u_{m n}^{r i g}\right)
\end{array}\right]
\end{aligned}
$$


Since different fuzzy attributes have different numerical types and dimensions, to guarantee the reliability and accuracy of the results, the indexes should have a unified scale, therefore, these fuzzy attributes need to be normalized. According to the established EISs, the fuzzy attributes contain forward fuzzy attributes and reverse fuzzy attributes.

Forward fuzzy attributes mean that the greater the fuzzy value of the attribute, the better the effect of online English teaching, and their normalization results are:

$$
\tilde{V}_{i j}=\left(v_{i j}^{l e f}, v_{i j}^{o p t}, v_{i j}^{r i g}\right)=\left(\frac{u_{i j}^{l e f}}{\max _{1 \leq i \leq m} u_{i j}^{r i g}}, \frac{u_{i j}^{o p t}}{\max _{1 \leq i \leq m} u_{i j}^{r i g}}, \frac{u_{i j}^{r i g}}{\max _{1 \leq i \leq m} u_{i j}^{r i g}}\right)
$$

Reverse fuzzy attributes mean that the smaller the fuzzy value of the attribute, the better the effect of online English teaching, and their normalization results are:

$$
\tilde{V}_{i j}=\left(v_{i j}^{l e f}, v_{i j}^{o p t}, v_{i j}^{r i g}\right)=\left(\frac{\min _{1 \leq i \leq m} u_{i j}^{l e f}}{u_{i j}^{r i g}}, \frac{\min _{1 \leq i \leq m} u_{i j}^{l e f}}{u_{i j}^{o p t}}, \frac{\min _{1 \leq i \leq m} u_{i j}^{l e f}}{u_{i j}^{l e f}}\right)
$$

Then, the corresponding normalized value matrix $\mathbf{V}$ of online English teaching effect evaluation can be established as:

$$
\begin{aligned}
& \mathbf{V}=\left[\begin{array}{ccccc}
\tilde{V}_{11} & \cdots & \tilde{V}_{1 j} & \cdots & \tilde{V}_{1 n} \\
\vdots & \vdots & \vdots & \vdots & \vdots \\
\tilde{V}_{i 1} & \cdots & \tilde{V}_{i j} & \cdots & \tilde{V}_{i n} \\
\vdots & \vdots & \vdots & \vdots & \vdots \\
\tilde{V}_{m 1} & \cdots & \tilde{V}_{m j} & \cdots & \tilde{V}_{m n}
\end{array}\right] \\
& =\left[\begin{array}{cccccc}
\left(v_{e 1}^{l e f}, v_{11}^{o p t}, v_{11}^{r i g}\right) & \cdots & \left(v_{1 j}^{l e f}, v_{1 j}^{o p t}, v_{1 j}^{r i g}\right) & \cdots & \left(v_{1 n}^{l e f}, v_{1 n}^{o p t}, v_{1 n}^{r i g}\right) \\
\vdots & \vdots & \vdots & \vdots & \vdots \\
\left(v_{i 1}^{l e f}, v_{i 1}^{o p t}, v_{i 1}^{r i g}\right) & \cdots & \left(v_{i j}^{l e f}, v_{i j}^{o p t}, v_{i j}^{r i g}\right) & \cdots & \left(v_{i n}^{l e f}, v_{i n}^{o p t}, v_{i n}^{r i g}\right) \\
\vdots & & \vdots & \vdots & \vdots & \vdots \\
\left(v_{m 1}^{l e f}, v_{m 1}^{o p t}, v_{m 1}^{r i g}\right) & \cdots & \left(v_{m j}^{l e f}, v_{m j}^{o p t}, v_{m j}^{r i g}\right) & \cdots & \left(v_{m n}^{l e f}, v_{m n}^{o p t}, v_{m n}^{r i g}\right)
\end{array}\right]
\end{aligned}
$$

\subsection{Weights of attributes of online English teaching effect evaluation based on the entropy method}

Above-established evaluation index systems show that, different indexes have different importance for the evaluation results of online English teaching effect, especially when the evaluation is conducted from different perspectives, the importance degree of different indexes should be divided in detail. The entropy method is an effective way to obtain the weights of evaluation indexes, due to its merits of objectivity, 
simple and effective calculation, and high reliability, this method is quite popular in actual engineering practice [18-20]. For this reason, this paper adopted it to determine the weights of the evaluation indexes.

Each column of the normalized value matrix $\mathbf{V}$ of online English teaching effect evaluation was subject to most likely value normalization, namely, there is:

$$
G_{i j}=\frac{\tilde{V}_{i j}}{\sum_{i=1}^{m} \tilde{V}_{i j}}=\frac{v_{i j}^{o p t}}{\sum_{i=1}^{m} v_{i j}^{o p t}}
$$

Then, the information entropy $E_{j}$ of the $j$-th index of online English teaching effect is:

$$
E_{j}=-\frac{1}{\ln m} \sum_{i=1}^{m}\left(G_{i j} * \ln G_{i j}\right)
$$

The weight value $W_{j}$ of the $j$-th index can be expressed as:

$$
w_{j}=\frac{1-E_{j}}{\sum_{j=1}^{n}\left(1-E_{j}\right)}
$$

\subsection{Fuzzy distance calculation model for online English teaching effect evaluation}

Knowing from the theory of fuzzy mathematics [21-24], if there are two triangular fuzzy numbers, $\tilde{V}_{a j}=\left(v_{a j}^{l e f}, v_{a j}^{o p t}, v_{a j}^{r i g}\right) \quad, \quad v_{a j}^{l e f} \leq v_{a j}^{o p t} \leq v_{a j}^{r i g} \quad$ and $\quad \tilde{V}_{b j}=$ $\left(v_{b j}^{l e f}, v_{b j}^{o p t}, v_{b j}^{r i g}\right), v_{b j}^{\text {lef }} \leq v_{b j}^{o p t} \leq v_{b j}^{r i g}$, the two can perform corresponding mathematical operations, the product of the two is:

$$
\tilde{V}_{a j} * \tilde{V}_{b j}=\left(v_{b j}^{l e f} * v_{a j}^{l e f}, v_{b j}^{o p t} * v_{a j}^{o p t}, v_{b j}^{r i g} * v_{a j}^{r i g}\right)
$$

The quotient of the two is:

$$
\tilde{V}_{a j} / \tilde{V}_{b j}=\left(v_{a j}^{l e f} / v_{b j}^{r i g}, v_{a j}^{o p t} / v_{b j}^{o p t}, v_{a j}^{r i g} / v_{b j}^{l e f}\right)
$$

Then, the fuzzy distance between the two is:

$$
D\left(\tilde{V}_{a j} \Leftrightarrow \tilde{V}_{b j}\right)=\sqrt{\frac{\left(v_{b j}^{l e f}-v_{a j}^{l e f}\right)^{2}+\left(v_{b j}^{o p t}-v_{a j}^{o p t}\right)^{2}+\left(v_{b j}^{r i g}-v_{a j}^{r i g}\right)^{2}}{3}}
$$


Through normalized value matrix $\mathbf{V}$ obtained above, the forward index value sequence $\mathbf{V}^{+}$of the $\mathrm{j}$-th index could be obtained as:

$$
\mathbf{V}^{+}=\left\{V_{1}^{+}, V_{2}^{+}, \cdots, V_{j}^{+}, \cdots, V_{n-1}^{+}, V_{n}^{+}\right\}
$$

where,

$$
V_{j}^{+}=\left(v_{j}^{l e f}(+), v_{j}^{o p t}(+), v_{j}^{r i g}(+)\right)=\left(\max _{1 \leq i \leq m} v_{i j}^{l e f}, \max _{1 \leq i \leq m} v_{i j}^{o p t}, \max _{1 \leq i \leq m} v_{i j}^{\text {rig }}\right)
$$

In the same way, the reverse index value sequence $\mathbf{V}^{-}$of the $\mathrm{j}$-th evaluation index could be obtained as:

$$
\mathbf{V}^{-}=\left\{V_{1}^{-}, V_{2}^{-}, \cdots, V_{j}^{-}, \cdots, V_{n-1}^{-}, V_{n}^{-}\right\}
$$

where,

$$
V_{j}^{-}=\left(v_{j}^{\text {lef }}(-), v_{j}^{\text {opt }}(-), v_{j}^{\text {rig }}(-)\right)=\left(\min _{1 \leq i \leq m} v_{i j}^{\text {lef }}, \min _{1 \leq i \leq m} v_{i j}^{\text {opt }}, \min _{1 \leq i \leq m} v_{i j}^{\text {rig }}\right)
$$

Therefore, the fuzzy distance between the $i$-th index and the forward index value sequence $\mathbf{V}^{+}$with respect to the $j$-th index can be described as $D^{+}\left(\tilde{V}_{i j} \Leftrightarrow V_{j}^{+}\right)$, namely:

$$
D^{+}\left(\tilde{V}_{i j} \Leftrightarrow \mathbf{V}^{+}\right) \sqrt{\frac{\left(v_{i j}^{l e f}-v_{j}^{l e f}(+)\right)^{2}+\left(v_{i j}^{o p t}-v_{j}^{o p t}(+)\right)^{2}+\left(v_{i j}^{r i g}-v_{j}^{r i g}(+)\right)^{2}}{3}}
$$

In the same way, the fuzzy distance between the $i$-th index and the reverse index value sequence $\mathbf{V}^{-}$with respect to the $j$-th index can be described as $D^{-}\left(\tilde{V}_{i j} \Leftrightarrow V_{j}^{-}\right)$, namely:

$$
D^{-}\left(\tilde{V}_{i j} \Leftrightarrow \mathbf{V}^{-}\right) \sqrt{\frac{\left(v_{i j}^{l e f}-v_{j}^{l e f}(-)\right)^{2}+\left(v_{i j}^{\text {opt }}-v_{j}^{\text {opt }}(-)\right)^{2}+\left(v_{i j}^{r i g}-v_{j}^{r i g}(-)\right)^{2}}{3}}
$$

\subsection{Realization of the fuzzy evaluation model}

Above data processing and analysis suggest that, the fuzzy distance $D^{+}\left(\tilde{V}_{i j} \Leftrightarrow\right.$ $\left.V_{j}^{+}\right)$and $D^{-}\left(\tilde{V}_{i j} \Leftrightarrow V_{j}^{-}\right)$between the i-th evaluation object and the forward and reverse index value sequence $\mathbf{V}^{+}$and $\mathbf{V}^{-}$can be obtained. In terms of the physical meaning, smaller $D^{+}\left(\tilde{V}_{i j} \Leftrightarrow V_{j}^{+}\right)$value indicates better teaching effect of object $i$; and larger $D^{-}\left(\tilde{V}_{i j} \Leftrightarrow V_{j}^{-}\right)$value indicates better teaching effect of object $i$. For this reason, the concept of fuzzy correlation degree of online English teaching effect evalua- 
tion is proposed here, the fuzzy correlation $\phi^{+}\left(\tilde{V}_{i j} \Leftrightarrow V_{j}^{+}\right)$between the i-th object and the forward index value sequence $\mathbf{V}^{+}$is:

$$
\phi^{+}\left(\tilde{V}_{i j} \Leftrightarrow V_{j}^{+}\right)=1-D^{+}\left(\tilde{V}_{i j} \Leftrightarrow V_{j}^{+}\right)
$$

The corresponding weighted fuzzy correlation degree is:

$$
\varpi^{+}\left(\tilde{V}_{i j} \Leftrightarrow V_{j}^{+}\right)=W_{j} * \phi^{+}\left(\tilde{V}_{i j} \Leftrightarrow V_{j}^{+}\right)
$$

The fuzzy correlation $\phi^{-}\left(\tilde{V}_{i j} \Leftrightarrow V_{j}^{-}\right)$between the $i$-th object and the reverse index value sequence $\mathbf{V}^{-}$is:

$$
\phi^{-}\left(\tilde{V}_{i j} \Leftrightarrow V_{j}^{-}\right)=1-D^{-}\left(\tilde{V}_{i j} \Leftrightarrow V_{j}^{-}\right)
$$

The corresponding weighted fuzzy correlation degree $\varpi^{-}\left(\tilde{V}_{i j} \Leftrightarrow V_{j}^{-}\right)$is:

$$
\varpi^{-}\left(\tilde{V}_{i j} \Leftrightarrow V_{j}^{-}\right)=W_{j} * \phi^{-}\left(\tilde{V}_{i j} \Leftrightarrow V_{j}^{-}\right)
$$

Thus, the comprehensive weighted fuzzy correlation degree $\varphi_{i}$ of the $i$-th object can be expressed as:

$$
\varphi_{i}=\frac{\varpi^{+}\left(\tilde{V}_{i j} \Leftrightarrow V_{j}^{+}\right)}{\varpi^{+}\left(\tilde{V}_{i j} \Leftrightarrow V_{j}^{+}\right)+\varpi^{-}\left(\tilde{V}_{i j} \Leftrightarrow V_{j}^{-}\right)}
$$

Greater $\varphi_{i}$ value indicates better teaching effect of the $i$-th object; conversely, smaller $\varphi_{i}$ value indicates worse teaching effect. Therefore, the online English teaching effect of the $i$-th object can be determined by the size of $\varphi_{i}$.

\section{Conclusion}

Directing at a few listed problems with the teaching effect appraisal of online English teaching, this paper developed a fuzzy evaluation model drawing on the theories of fuzzy mathematics. In the beginning, this paper pointed out a few deficiencies and problems lying in online English teaching, and established a set of EISs from the perspective of different parties. Then, an improved fuzzy evaluation model with multiple attributes was built for the target matter, which has offered a useful evidence for assessing the effect of online English teaching. 


\section{Acknowledgement}

1. 2019 (second batch) collaborative education project of Ministry of Education (No. 201902034036): Construction and Application of Interactive Multimedia Courseware Based on "Rain Class" - taking western cultural English course as an example.

2. The special project of teaching reform and exploration in Shaanxi University of Science and Technology in 2019, online and offline blending teaching project: Research and Practice of Blending Teaching of Western Culture English Course Based on "MOOC + Rain class".

\section{$7 \quad$ References}

[1] Rus, D. (2020). Creative Methodologies in Teaching English for Engineering Students. Procedia Manufacturing, 46: 337-343. https://doi.org/10.1016/j.promfg. 2020.03.049

[2] Al-Smadi, M.H. (2020). The Effect of Using Songs on Young English Learners' Motivation in Jordan, International Journal of Emerging Technologies in Learning, 15(24): 52-63. https://doi.org/10.3991/ijet.v15i24.19311

[3] Zuo, Y.J. (2020). Research on Online and Offline College English Mixed Teaching Mode Based on Network Platform. Journal of Hubei Open Vocational College, 33(3): 172-173. https://doi.org/10.3969/j.issn.2096-711X.2020.03.073

[4] Taat, M.S., Abdulbaki, K., Al-Saqqaf, A. (2020). The Impact of Lecture and Interactive Methods onStudent's English Competency, International Journal of Emerging Technologies in Learning, 15(20): 255-266. https://doi.org/10.3991/ijet.v15i20. 16683

[5] Camiciottoli, B.C., Campoy-Cubillo, M.C. (2018). Introduction: The nexus of multimodality, multimodal literacy, and English language teaching in research and practice in higher education settings. System, 2018,77: 1-9. https://doi.org/10.1016/j.system.2018. 03.005

[6] Li, Y. (2020). Research on college English network teaching based on massive open online course. Journal of Hubei Open Vocational College, 33(17): 179-180. https://doi.org/10.3969/j.issn.2096-711X.2020.17.080

[7] Tan, X.J., Chen, X.W., Gu, X.M., Liao, R.X. (2020). Study on the Blended Learning in Medical English Based on Online Teaching Platform: Taking the Teaching Practice of "Basic Medical English" as an Example. Medical Education Research and Practice, 28(5): 869-873. https://doi.org/10.13555/i.cnki.c.m.e.2020.05.034

[8] Chen, L.L. (2020). Research on ESP Teaching Practice of E-business English in Higher Vocational Education Based on Network Teaching Platform. Journal of Liuzhou Vocational \& Technical College, 20(5): 77-79. https://doi.org/10.16221/j.cnki.issn16711084.2020 .05 .018

[9] Ho, W.Y.J., Tai, K.W.H. (2020). Doing expertise multilingually and multimodally in online English teaching videos. System, 94: 1-12. https://doi.org/10.1016/j.system. 2020.102340

[10] Khattak, Z.I., Usman, M., Khan, R., Abbasi, G., Ahmad, A. (2011). Evaluation of the effectiveness of English language teaching in English language institutes in Mardan. Procedia-Social and Behavioral Sciences, 15: 1635-1638. https://doi.org/10.1016/j.sbspro. 2011.03.344 
[11] Yan, L.W., Kang, N., Gao, X.Y. (2020). The SPOC-based Construction of College English Teaching Quality Appraisal System. Journal of Changchun Education Institute, 36(3): 4045.

[12] Zhang, J.S. (2020). Evaluation of English Teaching Quality Based on GA Optimized RBF Neural Network. Computer Systems \& Applications, 29(3): 167-172. https://doi.org/10.15888/j.cnki.csa.007302

[13] Chen, Z.X. (2018). Research on the evaluation model of College English Teaching under modern network technology. Course Education Research, 5(18): 109-110. https://doi.org/10.16541/j.cnki.2095-8420.2018.18.048

[14] Li, H. (2016). Construction of College English teaching evaluation system under network mode. English teachers, 16(3): 6-8. https://doi.org/10.3969/j.issn.1009-8852.2016.03.001

[15] Wei, B., Zeng, Q.S. (2015). A Comprehensive Evaluation Method for Network Courses Learning-A Case Study on College English Network Course Teaching. Computer and Modernization, 11: 118-121. https://doi.org/10.3969/j.issn.1006-2475.2015.11.025

[16] Nirmala, G., Uthra, G. (2019). AHP based on Triangular Intuitionistic Fuzzy Number and its Application to Supplier Selection Problem. Materials Today: Proceedings, 16: 987-993. https://doi.org/10.1016/j.matpr.2019.05.186

[17] Karimi, H., Sadeghi-Dastaki, M., Javan, M. (2019). A fully fuzzy best-worst multi attribute decision making method with triangular fuzzy number: A case study of maintenance assessment in the hospitals. Applied Soft Computing, 86: 248-260. https://doi.org/10.1016/j.asoc.2019.105882

[18] Tuğal, I., Karc1, A. (2019). Comparisons of Karc1 and Shannon entropies and their effects on centrality of social networks. Physica A: Statistical Mechanics and its Applications, 523: 352-363. https://doi.org/10.1016/j.physa.2019.02.026

[19] Fedajev, A., Stanujkic, S., Karabašević, D., Brauers, W.K.M., Zavadskas, E.K. (2020). Assessment of progress towards "Europe 2020" strategy targets by using the MULTIMOORA method and the Shannon Entropy Index. Journal of Cleaner Production, 224: 1-12. https://doi.org/10.1016/j.jclepro.2019.118895

[20] Alao, M.A., Ayodele, T.R., Ogunjuyigbe, A.S.O., Popoola, O.M. (2020). Multi-criteria decision-based waste to energy technology selection using entropy-weighted TOPSIS technique: The case study of Lagos, Nigeria. Energy, 201: 1-14. https://doi.org/10.1016/ j.energy.2020.117675

[21] Saini, N., Bajaj, R.K., Gandotra, N., Dwivedi, R.P. (2018). Multi-criteria Decision Making with Triangular Intuitionistic Fuzzy Number based on Distance Measure \& Parametric Entropy Approach. Procedia Computer Science, 125: 34-41. https://doi.org/10.1016/ i.procs.2017.12.007

[22] Mandar, M., Karim, L., Boulmakoul, A., Lbath, A. (2017). Triangular intuitionistic fuzzy number theory for driver-pedestrian's interactions and risk exposure modeling. Procedia Computer Science, 109: 148-155. https://doi.org/10.1016/j.procs. 2017.05.309

[23] Seresht, N.G., Fayek, A.R. (2019). Computational method for fuzzy arithmetic operations on triangular fuzzy numbers by extension principle. International Journal of Approximate Reasoning, 106: 172-193. https://doi.org/10.1016/j.ijar.2019.01.005

[24] Molinari, F. (2016). A new criterion of choice between generalized triangular fuzzy numbers. Fuzzy Sets and Systems, 296: 51-69. https://doi.org/10.1016/j.fss. 2015.11.022 


\section{Author}

Yuqing Zhang was born in October 1980 in Xi'an City, Shaanxi Province, China. She received B.A. Degree in English from Xi'an International Studies University in 2003 and Master's Degree in Principles of Pedagogy in 2012. She started her career from 2003 in Shaanxi University of Science and Technology. She has authored more than 10 papers in English teaching and literature, compiled two academic monographs and one teaching material, presided over and participated in several municipal and university research projects. Email: zhangyqq113@163.com.

Article submitted 2021-04-15. Resubmitted 2021-05-25. Final acceptance 2021-05-25. Final version published as submitted by the authors. 